\title{
Impact of extrafine formulations of inhaled corticosteroids/long-acting beta-2 agonist combinations on patient-related outcomes in asthma and COPD
}

REVIEW

Nicola Scichilone'

Alida Benfante'

Luca Morandi²

Federico Bellini²

Alberto $\mathrm{Papi}^{2}$

'Biomedical Department of Internal and Specialist Medicine, Section of Pulmonology, University of Palermo, Italy; ${ }^{2}$ Respiratory Medicine, Department of Medical Sciences, University of Ferrara, Ferrara, Italy
Correspondence: Alberto Papi Respiratory Medicine, Department of Medical Sciences, University of Ferrara, Arcispedale Sant'Anna, Via Aldo Moro 8, Cona, 44I24 Ferrara, Italy

Tel +390532236908

Fax +390532 210297

Email ppa@unife.it
This article was published in the following Dove Press journal:

Patient Related Outcome Measures

27 November 2014

Number of times this article has been viewed

\begin{abstract}
Asthma and chronic obstructive pulmonary disease (COPD) are among the most common chronic diseases worldwide, characterized by a condition of variable degree of airway obstruction and chronic airway inflammation. A large body of evidence has demonstrated the importance of small airways as a pharmacological target in these clinical conditions. Despite a deeper understanding of the pathophysiological mechanisms, the epidemiological observations show that a significant proportion of asthmatic and COPD patients have a suboptimal (or lack of) control of their diseases. Different factors could influence the effectiveness of inhaled treatment in chronic respiratory diseases: patient-related (eg, aging); disease-related (eg, comorbid conditions); and drug-related/formulation-related factors. The presence of multiple illnesses is common in the elderly patient as a result of two processes: the association between age and incidence of degenerative diseases; and the development over time of complications of the existing diseases. In addition, specific comorbidities may contribute to impair the ability to use inhalers, such as devices for efficient drug delivery in the respiratory system. The inability to reach and treat the peripheral airways may contribute to the lack of efficacy of inhaled treatments. The recent development of inhaled extrafine formulations allows a more uniform distribution of the inhaled treatment throughout the respiratory tree to include the peripheral airways. The beclomethasone/formoterol extrafine formulation is available for the treatment of asthma and COPD. Different biomarkers of peripheral airways are improved by beclomethasone/formoterol extrafine treatment in comparison with equivalent nonextrafine inhaled corticosteroids/longacting beta-2 agonist (ICS/LABA) combinations. These improvements are associated with improved lung function and clinical outcomes, along with reduced systemic exposure to inhaled corticosteroids. The increased knowledge in the pathophysiology of the peripheral airways may lead to identify specific phenotypes of obstructive lung diseases that would mostly benefit from the treatments specifically targeting the peripheral airways.
\end{abstract}

Keywords: COPD, asthma, inhalational therapy, small airways

\section{Asthma and chronic obstructive pulmonary disease: unmet needs or unsatisfactory patient-physician relationships?}

Asthma and chronic obstructive pulmonary disease (COPD) are among the most common chronic diseases worldwide, characterized by a condition of variable degree of airway obstruction and chronic airway inflammation. ${ }^{1,2}$ The chronic features of the diseases need persistent treatment to reduce respiratory symptoms and to prevent 
the occurrence of exacerbations with the least possible amount of drugs. However, despite a deeper understanding of the pathophysiological mechanisms and the growing availability of new pharmacological compounds, as well as the applicability of modern pharmacological strategies to better manage the diseases, as well as higher attention and adherence to detailed treatment guidelines, epidemiological observations clearly show that a variable (not trivial) proportion of asthmatic and COPD patients have a suboptimal (or lack of) control of both diseases. ${ }^{3,4}$

In asthmatics, according to the Global Initiative for Asthma guidelines, ${ }^{1}$ disease control is evaluated by diurnal or nighttime symptoms, the limitation of daily activities including exercise, the use of beta- 2 agonists, pulmonary function test, exacerbations in the previous year, and shelter in emergency. This is also the case in COPD, where the combination of lung function impairment, the severity of respiratory symptoms, and the rate of exacerbations depict the overall characterization of the disease. ${ }^{2}$ The frequency of exacerbations in the previous years are the best predictor of the development of future exacerbations, long-term decline in lung function, and disability (ie, future risks)..$^{2,5-7}$

Several studies have tried to identify which factors are associated with treatment failure in patients affected by asthma or COPD. These factors include inadequate drug treatment and a lack of adherence to the recommended drug therapy, as well as to the proper use of the device. Moreover, observational investigations have led to the assumption that inadequate physician-patient communication contributes to the inability to attain optimal control, and that patients and physicians often underestimate the intensity and frequency of symptoms and the need to constantly monitor the disease. ${ }^{8,9}$

In asthmatics, both physiological and psychological factors influence the occurrence and the perception of respiratory symptoms; to confirm the influence of factors other than lung functional alterations on symptom severity, a weak correlation was demonstrated between the magnitude of airway obstruction and asthma symptoms. ${ }^{10}$ As described in two studies, patients often have inadequate information on their state, they tend not to trust the pharmacological treatment they are offered, and they are not convinced that drug therapy can completely control their symptoms. ${ }^{3,11}$ These observations support the notion that the lack of adherence to regular therapy impacts on the control of respiratory symptoms in chronic obstructive respiratory diseases.
It has been estimated that a lack of adherence involves up to $20 \%$ of patients who need treatment for a short period (10 days) because of an acute disease. ${ }^{12}$ Moreover, poor adherence occurs in $50 \%$ of patients affected by a chronic symptomatic disease and $70 \%$ of those affected by a chronic asymptomatic disease. Cramer et $\mathrm{al}^{13}$ assessed compliance with long-term medications among newly treated and longterm patients. Compliance rates averaged $76 \%$ during the study period; $87 \%$ for the once-daily, $81 \%$ for the twicedaily, $77 \%$ of the three times a day, and $39 \%$ of the four times a day dosages, demonstrating that adherence to treatment is influenced by the frequency of drug administration. The Italian Study on Asthma in Young Adults study showed that regular treatment was associated with a better control of symptoms for each degree of severity, eventually confirming that the inappropriate use of drugs is responsible, to a large extent, for the failure in controlling asthma. ${ }^{14,15}$ The authors found that $47 \%$ of persistent asthmatics who participated in the survey in Italy were using a combination therapy that was inadequate for the severity level (too low of a dosage of corticosteroids and/or inappropriate treatment); $64 \%$ of asthmatics were on an irregular treatment that should have been taken daily.

\section{Factors impairing the effectiveness of inhaled treatment}

Different factors could influence the effectiveness of inhaled treatment in chronic respiratory diseases; these can be summarized in patient-related, disease-related, and drug-related/ formulation-related factors. ${ }^{12,16}$ In addition, all factors that weaken the relationship between physicians and patients should be taken into consideration. ${ }^{8}$ When exploring conditions specifically associated with the patient, age per se appears to be the most influencing one. ${ }^{17-20}$ Comorbidity is considered one of the hallmarks of the geriatric patient population, and it is relevant with respect to drug therapy. Specific comorbidities may contribute to impair one's ability to use inhalator devices. For example, a strong relationship between cognitive function and the ability to acquire the metered dose inhaler (MDI) has been demonstrated. ${ }^{20}$ Among factors related to treatment, complex medical treatment that requires the use of different drugs, the use of different devices for inhalation therapy and the complexity of dosage, as well as the side effects of the medications should be taken into consideration in daily clinical practice. ${ }^{12}$ In this respect, high-dose regimens and long-term use of inhaled corticosteroids (ICSs) have the potential to cause a variety of side effects that are similar to those observed with systemic 
corticosteroid therapy. Among those, candidiasis, cataracts, glaucoma, and osteoporosis are the most common. The use of ICSs can also be associated with the increased risk of bone fractures, diabetes, and pneumonia..$^{21,22}$

These ICS-related systemic side effects are of particular importance in elderly patients due to the presence of comorbidities. This is also true for inhaled bronchodilators, which can be associated with an increased risk of cardiovascular events in patients at high risk. ${ }^{23}$

It is infrequent that the lack of asthma control is a direct consequence of a condition of drug-resistant disease. It is more likely that an uncontrolled condition is related to the underestimation of disease severity by physicians and patients with consequent prescription of insufficient medications and a low degree of adherence to treatment. Other disease-related factors should be evaluated; asthma and COPD are inflammatory disorders of the entire bronchial tree, including the more peripheral airways, although their involvement may remain functionally and clinically silent until features of air trapping and hyperinflation become evident, leading to a lack of symptom control despite conventional treatment. Indeed, it has been found that small airway dysfunction is associated with an increased risk of exacerbations and lower asthma control. In addition, recent studies documented a more severe impairment of the peripheral airways in patients with severe asthma. ${ }^{24-34}$

\section{Peripheral airways: a target for disease control}

Inflammatory and functional changes of the peripheral airways strongly contribute to the complexity and the heterogeneous manifestations of chronic obstructive diseases, suggesting that this site should not be neglected in the monitoring or in the development of treatments for diseases, such as asthma and COPD. ${ }^{27}$ Studies based on imaging, transbronchial biopsies, and autopsy specimens have confirmed the role of the peripheral airways in the most severe forms of asthma and in all stages of COPD. ${ }^{24-34} \mathrm{~A}$ more recent investigation has documented that inflammatory and structural changes of the peripheral airways are also associated with a lack of control in mild stages of asthma. ${ }^{35}$ To date, there is a general agreement on the involvement of the peripheral airways in the lack of symptom control, both in asthma and in COPD. In the last few years, great effort has been made to design methods of assessment of the peripheral airways' function and to formulate advancements for better drug delivery to this region of the lungs.
The relevance of peripheral airways should be carefully considered in the management of asthma and COPD for the assessment and prevention of future risk, which refers to the occurrence of exacerbations, a loss of symptom control, a faster rate of decline in lung function, or the side effects of treatment. In this respect, the detection of small airway abnormalities could potentially indicate patients who are at major risk of sudden attacks or more severe disease, or it may predict those likely to benefit from a specific intervention. ${ }^{36}$ These observations imply that functional or biological pathophysiological parameters, reflecting small airway involvement, might be used prognostically in chronic airway diseases.

The key point of the management of chronic obstructive respiratory diseases is to use inhalation therapy to access the target site, while directing delivery of the aerosolized drug to the airways with the aim of treating inflammation and relieving obstruction. The inhaled route of administration aims to exploit the topical effect directly near the site of deposition, minimizing the risk of systemic exposure. Indeed, oral administration carries the risk of adverse events, due to the high bioavailability of the drug. The bioavailability is the fraction of the drug that reaches systemic circulation through various organs and can be responsible for systemic adverse effects. Obviously, the compounds that are administered by inhalation and are detected in systemic circulation mainly originate from the amount deposited in the oropharynx, which is swallowed and then adsorbed through the gastrointestinal tract. In order to improve the deposition in the periphery of the bronchial tree, the aerodynamic size of a particle should be first established. Moreover, the drug deposition in the airways can be modulated by the type of device used, the aerosol formulation, and the patient's inhalation technique.

In this scenario, the achievement of the targeted site is obtained by complying with three conditions: 1) the drug delivery system should assure the generation of an aerosol cloud containing particles able to penetrate the respiratory tract; 2) the aerosol formulation should enable the drug to deposit along the respiratory tract; and 3) the deposition of the drug should translate into functional and clinical benefits.

The drug contained in the pressurized MDI (pMDI) is usually formulated in form of a suspension or a solution, which may variably affect the delivery characteristics, such as particle size, plume velocity, and duration..$^{37,38,57}$ Because of the fast-moving aerosol produced with the pMDI, the risk of deposition of the drug in the pharynx is high, thus reducing the clinical efficacy. ${ }^{39-41}$ One of the main issues associated with 
the suspension formulations, which is estimated to occur in a vast proportion of subjects, is the fact that these formulations need to be shaken before inhalation to allow for the uniform distribution of solid powder particles of the drug, so as to favor homogeneity of the drug concentration and result in dose consistency. Moreover, the suspension formulations may release large particles (due to the agglomeration of the micronized ones), of which only $10 \%-15 \%$ of the total dose achieves the conductive and lower peripheral airways. ${ }^{42}$ Because of the particle size, suspension formulations need a relatively larger orifice diameter to avoid its blocking by the emitted suspension, leading to higher velocity and lower duration of the aerosol plume.

The replacement of chlorofluorocarbon (CFC) propellants with hydrofluoroalkane (HFA) has allowed a shift from suspension formulations to solution formulations, where the drug is more uniformly distributed and the shaking of the inhaler is no longer necessary. The new HFA solution aerosols allow for the particle size to be modified within the respirable range (extrafine particles or coarser ones); this property leads to deeper penetration of the medication into the lung. ${ }^{43,44}$ In the context of developing new formulations aiming at improving the deposition of inhaled drugs in the lung, the Modulite ${ }^{\circledR}$ technology (Chiesi Farmaceutici SpA, Parma, Italy) was launched. The goal was to produce a slow-moving cloud containing particles of the required particle size, and this could be achieved with integration of device characteristics, propellant characteristics, drug formulation, and the patient's appropriate use. ${ }^{45}$ Modulite achieves this goal primarily by the geometry of the actuator orifice; indeed, the actuator geometry influences the cloud formation, since a smaller orifice produces more refined spray with slow-moving clouds over a much longer period, thus helping patients to coordinate the inspiratory maneuver with the generation of the cloud. In addition, changes in vapor pressure by mixing available propellants and the volume of the metering valve also contribute to optimize the delivery. The Modulite technology also uses the presence of a nonvolatile component to provide the targeted particle size. Indeed, the particle size depends on the drug concentration in a droplet and other nonvolatile components that are added; each droplet will eventually dry to result in a particle, the size of which depends on the concentration of the drug in the solution. These characteristics confirm that the Modulite technology is able to deliver drug particles within a desired range of particle sizes, which allows for uniform distribution along the bronchial tree to reach the peripheral airways.
In dry powder inhalers (DPIs), the drug is not driven by the propellant, but it is delivered by inhalation effort. Conversely, the actuation of the device and the amount of drug reaching the lower airways are dependent on the patient's peak inspiratory flow. ${ }^{46}$ This could highlight a crucial problem in the elderly population in whom the ability to generate sufficient inspiratory flow across a DPI is compromised, irrespective of the presence of an obstructive airway alteration. Three types of DPIs are available with different handling instructions: single-dose (eg, HandiHaler ${ }^{\circledR}$ [Boehringer Ingelheim, Ingelheim, Germany]; Ultibro ${ }^{\circledR}$ Breezhaler $^{\circledR}$ [Novartis International AG, Basel, Switzerland]; and Foradil ${ }^{\circledR}$ Aerolizer $^{\circledR}$ [Merck Millipore, Billerica, MA, USA]); multiple-dose (eg, Advair Diskus ${ }^{\circledR}$ [GlaxoSmithKline plc, London, UK]); and reservoir (eg, Symbicort Turbuhaler ${ }^{\circledR}$ [AstraZeneca plc, London, UK]) inhalers.

MDIs and DPIs require different techniques that imply specific training for each device: slow and deep inhalation for the MDIs; and inhalation that is quick, powerful, and as deep as possible for the DPIs. ${ }^{24,25,47}$ In addition, since DPIs are breath-actuated, they do not need coordination between activation and inhalation. More recently, other devices have been designed with the aim of limiting (or abolishing) the most common mistakes when using an inhaler. In this regard, the Fostair $^{\circledR}$ NEXThaler ${ }^{\circledR}$ (Chiesi Farmaceutici SpA), the Relvar $^{\circledR}$ Ellipta $^{\circledR}$ (GlaxoSmithKline plc), and the DuoResp Spiromax $^{\circledR}$ (Teva Pharmaceutical Industries Ltd, Petah Tikva, Israel) devices are novel and intuitively designed multidose DPIs, conceived for straightforward open-inhale-close operation that ensures ease of use. Indeed, the main scope of these new devices is to meet the needs of the patient, by simplifying the inhalation maneuvers and very likely improving adherence to treatment.

Taken together, these characteristics suggest that when selecting a device for patients with asthma and COPD, physicians should primarily consider the device/drug availability, the ability to use the selected device correctly, and the patient's preference. ${ }^{48}$ Indeed, differences in efficacy may be trivial when different devices are used with proper inhalation techniques and are well accepted by the patient. Of course, the issue remains of whether the targeted site is reached by the delivered drug when using different devices. The description of specific phenotypes, in which small airway abnormalities may play a relevant role, help to identify subgroups of patients for whom an extrafine formulation, which allows for the drugs to reach the periphery of the lung, may represent a specific and first-choice therapeutic option. Proper management of specific phenotypes of asthma and COPD should be based on 
drugs that are able to uniformly distribute along the bronchial tree and to reach the most peripheral airways.

\section{How to properly manage the diseases Inhaled treatment as first choice}

Inhaled therapy is the cornerstone of the daily control of obstructive respiratory diseases. In comparison with oral therapy, the inhaled pathway allows for the minimization of effective doses and consequently of adverse systemic effects, which is particularly relevant in long-term treatments. ${ }^{38} \mathrm{On}$ the other side, as stated previously, the inhaled pathway is affected by several variables, mostly related to the drug formulation and the delivery device. Direct delivery of the aerosolized drug in the lower airways is advocated to treat inflammation and to relieve obstruction. Studies have shown that asthma control can be obtained in the vast proportion of patients with inhaled steroids alone or in combination with LABAs.

ICSs are the first-line treatment for the management of asthma in that they are the most effective anti-inflammatory medications for the treatment of persistent asthma. There is vast evidence demonstrating the efficacy of ICSs in controlling airway inflammation, reducing symptoms, improving quality of life and lung function, decreasing airway hyperresponsiveness, reducing the frequency and severity of exacerbations, and even in reducing asthma mortality. ${ }^{49-53}$ International guidelines recommend the addition of an inhaled LABA to a low- to medium-dose ICS when low doses of ICSs fail to realize control of asthma symptoms. ${ }^{3}$ Randomized clinical trials with the LABA in combination with corticosteroids have demonstrated that the addition of LABA to ICSs is more beneficial in terms of asthma control and pulmonary function than increasing the dose of ICSs alone. ${ }^{52,54-57}$

The identification of the role of distal airways implies that the distribution of the drug along the bronchial tree translates into higher efficacy of the inhaled therapy in terms of functional and clinical benefits, and the reduction of adverse event rates. To date, there are some single-agent extrafine formulations on the market (beclomethasone, ciclesonide, and formoterol $[\mathrm{F}]$ ), and only one combination product available (beclomethasone/F). ${ }^{40}$ Extrafine solution pMDIs can deliver compounds with a mass median aerodynamic diameter that is smaller than that delivered by other available devices, resulting in a significant increase in peripheral airway drug deposition with respect to the delivered dose. ${ }^{58,59}$ Several studies demonstrated that ICS extrafine formulations alone were superior to nonextrafine formulations in modulating functional and inflammatory parameters, reflecting small airway abnormalities. ${ }^{60-62}$ In addition, it was calculated that 2.6-fold nonextrafine beclomethasone dipropionate (BDP) is required to achieve the same improvement in forced expiratory volume in the first second $\left(\mathrm{FEV}_{1}\right)$ as extrafine HFA-BDP. ${ }^{63}$

Subsequent clinical studies suggested that BDP extrafine $100 \mu \mathrm{g} /$ actuation alone is clinically equivalent to BDP nonextrafine pMDI $250 \mu \mathrm{g} /$ actuation in patients with moderate asthma, demonstrating a 1:2.5 equivalence ratio between extrafine and nonextrafine BDP. ${ }^{64,65}$ Moreover, in an openlabel, 12-month randomized controlled trial, Juniper et $\mathrm{al}^{66}$ showed that in asthmatic patients previously treated with nonextrafine CFC-BDP and switched to equipotent doses of extrafine HFA-BDP (one-half of the dose of the nonextrafine CFC-BDP), there was a significant improvement in asthma quality of life, as compared to those patients who continued to receive nonextrafine $\mathrm{CFC}$-BDP.

Another extrafine particle ICS formulation, namely ciclesonide, also showed functional changes, suggesting effective peripheral airway penetration. ${ }^{67}$ Ciclesonide administration was associated with an improvement in lung function and a reduction in airway hyperresponsiveness. In addition, ciclesonide demonstrated anti-inflammatory effects in the peripheral airways, as determined by decreased alveolar exhaled nitric oxide and reduced air trapping following a methacholine challenge in mild-to-moderate asthmatics. ${ }^{67}$ To date, no extrafine fixed combination of ciclesonide with LABA is available in the market.

\section{BDP/F extrafine formulation in asthma and COPD}

\section{Lung function and clinical outcomes}

The BDP/F HFA pMDI combination is an extrafine formulation, in which the BDP dose is 2.5 -fold lower than the conventional BDP CFC product $(100 \mu \mathrm{g}$ of BDP per actuation instead of $250 \mu \mathrm{g}$ of nonextrafine BDP). Furthermore, because of the small particle size of BDP/F, the two active drugs are delivered to both the central and peripheral airways, resulting in a uniform treatment of inflammation and bronchoconstriction throughout the lower respiratory tract. ${ }^{38}$ The reduction in BDP dose lowers the amount of drug deposited in the upper airway and contributes to systemic exposure, therefore potentially improving the efficacy/safety ratio. This would translate the efficacy of the drugs into greater effectiveness in clinical practice. The efficacy of BDP/F fixed combination was first evaluated in a 3-month trial conducted in patients with moderate asthma who were still symptomatic 
despite receiving low-dose ICSs (up to $500 \mu \mathrm{g} /$ day BDP or equivalent). ${ }^{68} \mathrm{BDP} / \mathrm{F}$ given at one inhalation twice daily proved to be more effective at improving lung function than a double equipotent dosage of BDP nonextrafine.

A second investigation was carried out in patients with more severe asthma. In this setting, $\mathrm{BDP} / \mathrm{F}$ given as two inhalations twice daily was as effective as nonextrafine BDP and $\mathrm{F}$ administered via separate inhalers, and superior to nonextrafine BDP alone in improving lung function. ${ }^{69}$ In addition, $\mathrm{BDP} / \mathrm{F}$ was significantly superior to separate components for asthma control. ${ }^{61}$ In this respect, Huchon et $\mathrm{al}^{70}$ showed that after 24 weeks of treatment extrafine BDP/F delivered by an HFA pMDI (400/24 $\mu \mathrm{g})$ was superior in improving asthma control to the combination of the same drugs formulated as larger nonextrafine agents at equipotent doses $(1,000 \mu \mathrm{g}$ BDP $+24 \mu \mathrm{g} \mathrm{F})$. Moreover, in two randomized clinical studies with a similar design, Papi et al ${ }^{71,72}$ reported that the extrafine combination of $\mathrm{BDP} / \mathrm{F}$ was comparable to the nonextrafine combinations of budesonide (BUD)/F (Turbuhaler BUD/F) and fluticasone propionate/salmeterol (pMDI FP/S) at equipotent doses in terms of lung function improvement, as measured by morning peak expiratory flow changes. When functional parameters more related to peripheral airway abnormalities were considered, 12 weeks of extrafine BDP/F combination treatment was significantly superior to an equipotent dose of the nonextrafine FP/S combination in improving air trapping, estimated by a reduction in forced vital capacity. These results provide direct evidence of the superiority of the extrafine ICS/LABA combinations compared to the nonextrafine combinations in improving small airway function. Data from clinical trials did not document any increased risk of systemic effects with either a single inhaled ICS extrafine formulation, or a combination of ICS/LABA extrafine therapy compared with nonextrafine therapy. ${ }^{72,73}$ An interesting observation from the study by Papi et $\mathrm{al}^{72}$ was the more rapid bronchodilation with the extrafine formulation than with the FP/S group, which leads to a more immediate relief of symptoms and to a potentially greater rate of adherence in clinical practice.

The superiority of extrafine combination treatment in improving the functional parameters of the peripheral airways, as compared to nonextrafine combinations, was demonstrated by Scichilone et $\mathrm{al}^{74}$ in a double-blind randomized study performed in 30 asthmatics, for a period of 12 weeks: the extrafine BDP/F combination treatment tended to be significantly superior to equipotent doses of nonextrafine $\mathrm{FP} / \mathrm{S}$ in improving closing capacity measured by the single-breath $\mathrm{N}_{2}$ washout test, and it significantly decreased the degree of airway hyperresponsiveness, suggesting a homogeneous distribution of the drug throughout the bronchial tree.

The safety and efficacy of the fixed combination of $\mathrm{BDP} / \mathrm{F}$ have been confirmed in different levels of asthma severity. Singh et $\mathrm{al}^{75}$ investigated the acute tolerability of high, cumulative doses of BDP/F compared to $\mathrm{F}$ alone and placebo. They showed that when asthmatics, who were regularly treated for 4 weeks with BDP/F 100/6 $\mu \mathrm{g}$ as two inhalations twice daily, were given ten additional doses of $\mathrm{BDP} / \mathrm{F} 100 / 6 \mu \mathrm{g}, \mathrm{F} 6 \mu \mathrm{g}$, or placebo on 3 different days (days 14, 21, and 28 of the study), changes in vital signs were similar with high-dose BDP/F and high-dose $\mathrm{F}$, but they were not considered clinically significant. These findings demonstrated that the administration of high cumulative doses of BDP/F in addition to maintenance therapy has a satisfactory tolerability profile and is at least as safe as the administration of high doses of $\mathrm{F}$ alone. This observation has obvious consequences in clinical practice based on the safety profile of the extrafine combination treatment. With regards to the effectiveness of the extrafine combination in a real-life scenario, several studies have been conducted in the last few years. ${ }^{76,77} \mathrm{~A}$ real-life observational study was conducted by Müller et $\mathrm{al}^{76}$ to compare the asthma control efficacy of a BDP/F pMDI extrafine formulation versus nonextrafine formulations, such as BUD/F and FP/S combinations, both delivered as DPIs. In this real-life setting, the proportion of patients achieving asthma control was significantly higher in the BDP/F extrafine group than in the nonextrafine $\mathrm{BUD} / \mathrm{F}$ or $\mathrm{FP} / \mathrm{S}$ group, and this was achieved with a significantly lower ICS mean daily dose. This observation was confirmed in a larger observational study (PRospectIve Study on asthMA control [PRISMA] study ${ }^{77}$ ), showing that the extrafine BDP/F combination was more efficacious than the larger particle BUD/F and FP/S formulations in achieving asthma control and improving quality of life, respectively.

The prospective phase of the PRISMA study ${ }^{78}$ included 1,017 patients with uncontrolled $(55.7 \%)$ or partly controlled asthma (44.3\%). The 1-year monitoring in the real-life setting showed that the extrafine fixed combination provides better symptom control and quality of life than the nonextrafine fixed combinations (BUD/F or FP/S). These studies confirm that the extrafine inhaled combination impacts patient outcomes in real life. Whether the beneficial effect of extrafine formulations compared to nonextrafine formulations on asthma control is primarily due to improvements of small airway function, or is rather a consequence of a better 
distribution of the delivered drugs throughout the bronchial tree, is an interesting point of speculation.

The technology behind the extrafine formulation is able to optimize the duration and velocity of the aerosol plume as compared to reference CFC formulations. ${ }^{45}$ As discussed previously in "Peripheral airways: a target for disease control" lower plume velocities and increased plume duration mean that the dose may be generated over a prolonged period, and this represents a significant advancement in the improvement of hand-breath coordination in the use of pMDIs. From a clinical standpoint, the generation of a slow-moving cloud over a longer period may contribute to improved adherence to treatment, thus optimizing symptom control, especially in elderly individuals. Moreover, the nominal dose reduction of BDP results in a reduced systemic exposure, showing a low potential for inducing side effects.

The efficacy of extrafine combination treatment in improving the functional parameters of peripheral airways (as compared to nonextrafine combinations), and its safety, were also evaluated in COPD subjects. A body of evidence shows that functional alterations of the small airways play a central role in the pathophysiology of COPD. Sturton et $\mathrm{al}^{79}$ demonstrated that the small airways provide a greater contribution to airflow limitation in COPD than decreased elastic recoil as a result of emphysema. Indeed, a chronic inflammatory infiltrate is present in both the central and peripheral airways of patients with COPD. ${ }^{80}$ Significant correlations between lung function, airway wall area, and the inflammatory infiltrate in the small airways of patients with COPD were found. ${ }^{81}$ Notably, a positive correlation between the severity of COPD and the number of lymphoid follicles in the small airways has also been observed. ${ }^{80}$ In a study on patients with severe COPD, subjects were randomized to receive extrafine $\mathrm{BDP} / \mathrm{F}$ (200/12 mg pMDI), BUD/F (400/12 mg DPI), or F (12 $\mathrm{mg}$ DPI) twice daily for 48 weeks. It was shown that the use of $\mathrm{BDP} / \mathrm{F}$ for 48 weeks improved $\mathrm{FEV}_{1}$ to the same degree as BUD/F with a nominal dose of beclomethasone, which was twofold lower than the equipotent daily dose of BUD. ${ }^{82}$

Moreover, the improvement in predose forced vital capacity versus baseline was statistically significant for $\mathrm{BDP} / \mathrm{F}$ $(P=0.005)$, but not for BUD/F or $\mathrm{F}$. This is consistent with a more efficient peripheral deposition and reduction of air trapping. In addition, the distance covered in the 6-minute walking test at week 48 was significantly greater versus baseline in all the three groups. The change in distance covered was higher, though not statistically significant, in the BDP/F group than in the other groups.

Tzani et al ${ }^{83}$ designed a study to evaluate whether an extrafine combination of BDP/F was effective in reducing air trapping in COPD patients with hyperinflation, as compared with $\mathrm{FP} / \mathrm{S}$ combination treatment. ${ }^{83}$ The authors showed that $\mathrm{BDP} / \mathrm{F}$ extrafine combination is effective in reducing air trapping and dyspnea in COPD patients with lung hyperinflation. As a sign of peripheral activity, a significantly greater reduction in residual volume was observed in the BDP/F arm.

In the FORWARD study, the aim was to test the superiority of extrafine BDP/F 100/6 mg, two inhalations twice a day, over extrafine $\mathrm{F}$ alone in severe COPD patients with a history of exacerbations.$^{84}$ Primary outcomes were frequency of exacerbations and $\mathrm{FEV}_{1}$ at the end of the study. A total of 1,693 patients were screened, 1,199 of whom were randomized to $\mathrm{BDP} / \mathrm{F}$ or $\mathrm{F}$ groups. As compared to $\mathrm{F}$ alone, extrafine $\mathrm{BDP} / \mathrm{F}$ was shown to significantly reduce the exacerbation rate, prolong the time to first exacerbation, improve lung function assessed by predose morning $\mathrm{FEV}_{1}$, and improve the St. George's Respiratory Questionnaire total score.

Very recently, the first extrafine fixed combination of $\mathrm{BDP} / \mathrm{F}$ inhaled from an innovative DPI called NEXThaler was introduced. This extrafine powder, multidose, breathactuated inhaler incorporates a novel full-dose feedback system providing accurate dose metering and consistent full-dose release, independent of the respiratory flow. ${ }^{85,86,87}$ The extrafine BDP/F fixed combination, therefore, represents the only extrafine combination in both the pMDI and DPI formulations developed thus far. A scintigraphic study confirmed high lung deposition and homogeneous distribution throughout the entire bronchial tree, both in healthy subjects and in asthma and COPD patients. This device could meet and satisfy the needs of patients with obstructed airways who often suffer from a lack of ability in performing the correct inhalation maneuvers.

Indeed, inhaler mishandling is not only a waste, but it may have relevant clinical consequences in terms of unscheduled health care resource use and disease control. In a multicenter Italian study, ${ }^{88}$ inhaler misuse was associated with increased risk of hospitalization, emergency room visits, courses of oral steroids, and antimicrobials. In addition, the relationship between inhaler misuse and disease control measured by Asthma Control Test score was significant for both the asthmatic group alone and the whole population. ${ }^{88}$ In a recent study, ${ }^{89}$ a higher percentage of asthma patients was able to use the NEXThaler without errors when compared to Diskus and Turbuhaler. In the same study, NEXThaler was rated as 
the easiest to open, to prepare and set a dose, the easiest to tell how many doses were left, and the easiest instructions for use to understand. ${ }^{89}$

\section{Conclusion}

In conclusion, asthma and COPD are among the most common chronic diseases worldwide, and they are characterized by a variable degree of airway obstruction and chronic airway inflammation. A large body of evidence has demonstrated the importance of the small airways as a pharmacological target in these clinical conditions. Despite gaining a deeper understanding of the pathophysiological mechanisms, epidemiological observations show that a significant proportion of asthmatic and COPD patients have suboptimal (or a lack of) control of their diseases. The inability to reach and treat the peripheral airways may contribute to the lack of efficacy of inhaled treatments. The recent development of inhaled extrafine formulations allows for the more uniform distribution of the inhaled treatment throughout the respiratory tree to include the peripheral airways. These formulations are more effective and require a lower nominal dose to achieve the same effect on lung function and symptoms when compared to equipotent doses of nonextrafine formulations.

The beclomethasone/F extrafine formulation is available for the treatment of asthma and COPD. Different biomarkers of peripheral airways are improved by beclomethasone/F extrafine treatment in comparison with equivalent nonextrafine ICS/LABA combinations. This is associated with improved clinical outcomes, along with reduced systemic exposure to ICSs. The increased knowledge in the pathophysiology of the peripheral airways may lead to the identification of specific phenotypes of obstructive lung diseases that would mostly benefit from treatments specifically targeting the peripheral airways.

\section{Disclosure}

The authors report no conflicts of interest in this work.

\section{References}

1. Global Initiative for Asthma (GINA) [homepage on the Internet]. Global Initiative for Asthma Management and Prevention 2014. Available from: http://www.ginasthma.org/. Accessed October 27, 2014.

2. Global Initiative for Chronic Obstructive Lung Disease (GOLD) [homepage on the Internet]. Global Strategy for the Diagnosis, Management and Prevention of COPD. Global Initiative for Chronic Obstructive Lung Disease (GOLD); 2013. Available from: http://www.goldcopd.org. Accessed October 27, 2014.

3. Holgate ST, Price D, Valovirta E. Asthma out of control? A structured review of recent patient surveys. BMC Pulm Med. 2006:6 Suppl 1:S2-S10.
4. Demoly P,Gueron B, Annunziata K, Adamek L, Walters RD. Update on asthma control in five European countries: results of a 2008 survey. Eur Respir Rev. 2010;19(116):150-157.

5. Haselkorn T, Zeiger RS, Chipps BE, et al. Recent asthma exacerbations predict future exacerbations in children with severe or difficult-to-treat asthma. J Allergy Clin Immunol. 2009;124(5):921-927.

6. National Heart, Lung, and Blood Institute [webpage on the Internet]. Guidelines for the diagnosis and management of asthma. Bethesda, MD: National Heart, Lung, and Blood Institute; 2012. Available from: http://www.nhlbi.nih.gov/guidelines/asthma/asthgdln.htm. Accessed October 28, 2014.

7. British Thoracic Society Scottish Intercollegiate Guidelines Network. British Guideline on the Management of Asthma. Thorax. 2008; 63 Suppl 4:iv1-iv121.

8. Fuertes JN, Mislowack A, Bennett J, et al. The physician-patient working alliance. Patient Educ Couns. 2006;66(1):29-36.

9. Corsico AG, Cazzoletti L, de Marco R, et al. Factors affecting adherence to asthma treatment in an international cohort of young and middle-aged adults. Respir Med. 2007;101(6):1363-1367.

10. Apter AJ, Affleck G, Reisine ST, et al. Perception of airway obstruction in asthma: sequential daily analyses of symptoms, peak expiratory flow rate, and mood. J Allergy Clin Immunol. 1997;99(5):605-612.

11. Koning CJ, Maillé AR, Stevens I, Dekker FW. Patients' opinions on respiratory care: do doctors fulfill their needs? J Asthma. 1995;32(5): 355-363.

12. Claxton AJ, Cramer J, Pierce C. A systematic review of the associations between dose regimens and medication compliance. Clin Ther. 2001;23(8):1296-1310.

13. Cramer JA, Mattson RH, Prevey ML, Scheyer RD, Ouellette VL. How often is medication taken as prescribed? A novel assessment technique. JAMA. 1989;261(22):3273-3277.

14. de Marco R, Bugiani M, Cazzoletti L, et al; ISAYA study group. The control of asthma in Italy. A multicentre descriptive study on young adults with doctor diagnosed current asthma. Allergy. 2003;58(3):221-228.

15. de Marco R, Cazzoletti L, Cerveri I, et al; ISAYA Study Group. Are the asthma guideline goals achieved in daily practice? A population-based study on treatment adequacy and the control of asthma. Int Arch Allergy Immunol. 2005;138(3):225-234.

16. Barber N, Parsons J, Clifford S, Darracott R, Horne R. Patients' problems with new medication for chronic conditions. Qual Saf Health Care. 2004;13(3):172-175.

17. Graves MM, Adams CD, Portnoy JM. Adherence in young children with asthma. Curr Opin Allergy Clin Immunol. 2006;6(2):124-127.

18. Rubin BK. Inhaled corticosteroids: devices and deposition. Paediatr Respir Rev. 2004;5(Suppl A):S103-S106.

19. Bender B, Zhang L. Negative affect, medication adherence, and asthma control in children. J Allergy Clin Immunol. 2008;122(3):490-495.

20. Allen SC, Jain M, Ragab S, Malik N. Acquisition and short-term retention of inhaler techniques require intact executive function in elderly subjects. Age Ageing. 2003;32(3):299-302.

21. Loke YK, Cavallazzi R, Singh S. Risk of fractures with inhaled corticosteroids in COPD: systematic review and meta-analysis of randomised controlled trials and observational studies. Thorax. 2011;66(8): 699-708.

22. Sobieraj DM, White CM, Coleman CI. Benefits and risks of adjunctive inhaled corticosteroids in chronic obstructive pulmonary disease: a meta-analysis. Clin Ther. 2008;30(8):1416-1425.

23. Hawkins NM, Petrie MC, Macdonald MR, et al. Heart failure and chronic obstructive pulmonary disease the quandary of Beta-blockers and Beta-agonists. J Am Coll Cardiol. 2011;57(21):2127-2138.

24. The ENFUMOSA cross-sectional European multicentre study of the clinical phenotype of chronic severe asthma. European Network for Understanding Mechanisms of Severe Asthma. Eur Respir J. 2003;22(3):470-477.

25. Sorkness RL, Bleecker ER, Busse WW, et al; National Heart, Lung, and Blood Institute Severe Asthma Research Program. Lung function in adults with stable but severe asthma: air trapping and incomplete reversal of obstruction with bronchodilation. J Appl Physiol (1985). 2008;104(2):394-403. 
26. Hamid Q, Song Y, Kotsimbos TC, et al. Inflammation of small airways in asthma. J Allergy Clin Immunol. 1997;100(1):44-51.

27. Tulic MK, Christodoulopoulos P, Hamid Q. Small airway inflammation in asthma. Respir Res. 2001;2(6):333-339.

28. Burgel PR. The role of small airways in obstructive airway diseases. Eur Respir Rev. 2011;20(119):23-33.

29. Contoli M, Bousquet J, Fabbri LM, et al. The small airways and distal lung compartment in asthma and COPD: a time for reappraisal. Allergy. 2010;65(2):141-151.

30. Carroll N, Cooke C, James A. The distribution of eosinophils and lymphocytes in the large and small airways of asthmatics. Eur Respir J. 1997;10(2):292-300.

31. Wagner EM, Bleecker ER, Permutt S, Liu MC. Direct assessment of small airways reactivity in human subjects. Am J Respir Crit Care Med. 1998;157(2):447-452.

32. Balzar S, Wenzel SE, Chu HW. Transbronchial biopsy as a tool to evaluate small airways in asthma. Eur Respir J. 2002;20(2):254-259.

33. Ueda T, Niimi A, Matsumoto H, et al. Role of small airways in asthma: investigation using high-resolution computed tomography. J Allergy Clin Immunol. 2006;118(5):1019-1025.

34. Dolhnikoff M, da Silva LF, de Araujo BB, et al. The outer wall of small airways is a major site of remodeling in fatal asthma. J Allergy Clin Immunol. 2009;123(5):1090-1097.

35. Caramori G, Pandit A, Papi A. Is there a difference between chronic airway inflammation in chronic severe asthma and chronic obstructive pulmonary disease? Curr Opin Allergy Clin Immunol. 2005;5(1):77-83.

36. Contoli M, Kraft M, Hamid Q, et al. Do small airway abnormalities characterize asthma phenotypes? In search of proof. Clin Exp Allergy. 2012;42(8):1150-1160.

37. Bousquet J, Poli G, Acerbi, Monno R, Ramael S, Nollevaux F. Systemic exposure and implications for lung deposition with extra-fine hydrofluoroalkane beclometasone dipropionate/formoterol fixed combination. Clin Pharmacokinet. 2009;48(6):347-358.

38. De Backer W, Devolder A, Poli G, et al. Lung deposition of BDP/ formoterol HFA pMDI in healthy volunteers, asthmatic, and COPD patients. J Aerosol Med Pulm Drug Deliv. 2010;23(3):137-148.

39. Lavorini $F$. The challenge of delivering therapeutic aerosols to asthma patients. ISRN Allergy. 2013;2013:102418.

40. Laube BL, Janssens HM, de Jongh FH, et al; European Respiratory Society; International Society for Aerosols in Medicine. What the pulmonary specialist should know about the new inhalation therapies. Eur Respir J. 2011;37(6):1308-1331.

41. Hess DR. Aerosol delivery devices in the treatment of asthma. Respir Care. 2008;53(6):699-723; discussion 723-725.

42. Giraud V, Roche N. Misuse of corticosteroid metered-dose inhaler is associated with decreased asthma stability. Eur Respir $J$. 2002;19(2):246-251

43. Ganderton D, Lewis D, Davies R, Meakin B, Brambilla G, Church T. Modulite: a means of designing the aerosols generated by pressurized metered dose inhalers. Respir Med. 2002;96(Suppl D):S3-8.

44. Lewis DA, Ganderton D, Meakin BJ, Brambilla G. Modulite: a simple solution to a difficult problem. Respiration 2005;72(Suppl 1):3-5.

45. Acerbi D, Brambilla G, Kottakis I. Advances in asthma and COPD management: delivering CFC-free inhaled therapy using Modulite technology. Pulm Pharmacol Ther. 2007;20(3):290-303.

46. Tarsin WY, Pearson SB, Assi KH, Chrystyn H. Emitted dose estimates from Seretide Diskus and Symbicort Turbuhaler following inhalation by severe asthmatics. Int J Pharm. 2006;316(1-2):131-137.

47. Chrystyn H, Price D. Not all asthma inhalers are the same: factors to consider when prescribing an inhaler. Prim Care Respir J. 2009;18(4): 243-249.

48. Dolovich MB, Ahrens RC, Hess DR, et al; American College of Chest Physicians; American College of Asthma, Allergy, and Immunology. Device selection and outcomes of aerosol therapy: Evidence-based guidelines: American College of Chest Physicians/American College of Asthma, Allergy, and Immunology. Chest. 2005;127(1): 335-371.
49. Jeffery PK, Godfrey RW, Adelroth E, Nelson F, Rogers A, Johansson SA. Effects of treatment on airway inflammation and thickening of basement membrane reticular collagen in asthma. A quantitative light and electron microscopic study. Am Rev Respir Dis. 1992;145(4 Pt 1):890-899.

50. Juniper EF, Kline PA, Vanzieleghem MA, Ramsdale EH, O’Byrne PM, Hargreave FE. Effect of long-term treatment with an inhaled corticosteroid (budesonide) on airway hyperresponsiveness and clinical asthma in nonsteroid-dependent asthmatics. Am Rev Respir Dis. 1990;142(4):832-836.

51. The Childhood Asthma Management Program Research Group. Longterm effects of budesonide or nedocromil in children with asthma. N Engl J Med. 2000;343(15):1054-1063.

52. Pauwels RA, Löfdahl CG, Postma DS, et al. Effect of inhaled formoterol and budesonide on exacerbations of asthma. Formoterol and Corticosteroids Establishing Therapy (FACET) International Study Group. N Engl J Med. 1997;337(20):1405-1411.

53. Suissa S, Ernst P, Benayoun S, Baltzan M, Cai B. Low-dose inhaled corticosteroids and the prevention of death from asthma. NEngl J Med. 2000;343(5):332-336.

54. Lalloo UG, Malolepszy J, Kozma D, et al. Budesonide and formoterol in a single inhaler improves asthma control compared with increasing the dose of corticosteroid in adults with mild-to-moderate asthma. Chest. 2003;123(5):1480-1487.

55. Ringdal N. Long-acting beta2-agonists or leukotriene receptor antagonists as add-on therapy to inhaled corticosteroids for the treatment of persistent asthma. Drugs. 2003;63 Suppl 2:21-33.

56. Bateman ED, Bantje TA, João Gomes M, et al. Combination therapy with single inhaler budesonide/formoterol compared with high dose of fluticasone propionate alone in patients with moderate persistent asthma. Am J Respir Med. 2003;2(3):275-281.

57. Greening AP, Ind PW, Northfield M, Shaw G. Added salmeterol versus higher-dose corticosteroid in asthma patients with symptoms on existing inhaled corticosteroid. Allen and Hanburys Limited UK Study Group. Lancet. 1994;344(8917):219-224.

58. Fabbri LM, Nicolini G, Olivieri D, Papi A. Inhaled beclometasone dipropionate/formoterol extra-fine fixed combination in the treatment of asthma: evidence and future perspectives. Expert Opin Pharmacother. 2008;9(3):479-490.

59. Nicolini G, Scichilone N, Bizzi A, Papi A, Fabbri LM. Beclomethasone/ formoterol fixed combination for the management of asthma: patient considerations. Ther Clin Risk Manag. 2008;4(5):855-864.

60. Hauber H, Taha R, Bergeron C, Migounov V, Hamid Q, Olivenstein R. Effects of hydrofluoroalkane and dry powder-formulated corticosteroids on sputum inflammatory markers in asthmatic patients. Can Respir J. 2006;13(2):73-78.

61. Goldin JG, Tashkin DP, Kleerup EC, et al. Comparative effects of hydrofluoroalkane and chlorofluorocarbon beclomethasone dipropionate inhalation on small airways: assessment with functional helical thin-section computed tomography. J Allergy Clin Immunol. 1999;104(6):S258-S267.

62. Verbanck S, Schuermans D, Paiva M, Vincken W. The functional benefit of anti-inflammatory aerosols in the lung periphery. J Allergy Clin Immunol. 2006;118(2):340-346.

63. Busse WW, Brazinsky S, Jacobson K, et al. Efficacy response of inhaled beclomethasone dipropionate in asthma is proportional to dose and is improved by formulation with a new propellant. JAllergy Clin Immunol. 1999;104(6):1215-1222.

64. Dhillon S, Keating GM. Beclometasone dipropionate/formoterol: in an HFA-propelled pressurised metered-dose inhaler. Drugs. 2006;66(11):1475-1483; discussion 1484-1485.

65. Rigamonti E, Kottakis I, Pelc M, Grzelewska Rzymowska I. Feschenko Y. Comparison of a new extra-fine beclomethasone dipropionate HFA 134a-formulated pMDI with a standard BDP CFC pMDI in adults with moderate persistent asthma. Eur Respir J. 2006;28(Suppl 50):1236.

66. Juniper EF, Price DB, Stampone PA, Creemers JP, Mol SJ, Fireman P. Clinically important improvements in asthma-specific quality of life, but no difference in conventional clinical indexes in patients changed from conventional beclomethasone dipropionate to approximately half the dose of extrafine beclomethasone dipropionate. Chest. 2002;121(6): 1824-1832. 
67. Cohen J, Douma WR, ten Hacken NH, Vonk JM, Oudkerk M, Postma DS. Ciclesonide improves measures of small airway involvement in asthma. Eur Respir J. 2008;31(6):1213-1220.

68. Bonnet-Gonod F, Kottakis I, Ballabio M, et al. Superior efficacy of a low daily dose of a new fixed combination of beclomethasone dipropionate/ formoterol pMDI compared to increased daily dose of BDP in moderate persistent asthma: a 3 month clinical study. Eur Respir J. 2006;28(Suppl 50): 1237.

69. Bonnet-Gonod F, Kottakis I, Hofman T, Dymek L, Bousquet J. Beclomethasone dipropionate/formoterol in a single inhaler improves lung function and clinically meaningful outcomes in moderate to severe asthma. Eur Respir J. 2006;28(Suppl 50):1230.

70. Huchon G, Magnussen H, Chuchalin A, Dymek L, Gonod FB, Bousquet J. Lung function and asthma control with beclomethasone and formoterol in a single inhaler. Respir Med. 2009;103(1):41-49.

71. Papi A, Paggiaro PL, Nicolini G, Vignola AM, Fabbri LM; Inhaled Combination Asthma Treatment versus SYmbicort (ICAT SY) Study Group. Beclomethasone/formoterol versus budesonide/ formoterol combination therapy in asthma. Eur Respir J. 2007;29(4): 682-689.

72. Papi A1, Paggiaro P, Nicolini G, Vignola AM, Fabbri LM; ICAT SE study group. Beclomethasone/formoterol vs fluticasone/salmeterol inhaled combination in moderate to severe asthma. Allergy. 2007;62(10): 1182-1188.

73. Van Schayck CP, Donnell D. The efficacy and safety of QVAR (hydrofluoroalkane-beclometasone diproprionate extrafine aerosol) in asthma (part 1): an update of clinical experience in adults. Int $J$ Clin Pract. 2004;58(7):678-688.

74. Scichilone N, Battaglia S, Sorino C, et al. Effects of extra-fine inhaled beclomethasone/formoterol on both large and small airways in asthma. Allergy. 2010;65(7):897-902.

75. Singh D, Piccinno A, Borrill Z, et al. Tolerability of high cumulative doses of the HFA modulite beclomethasone dipropionate/formoterol combination inhaler in asthmatic patients. Pulm Pharmacol Ther. 2008; 21(3):551-557.

76. Müller V, Gálffy G, Eszes N, et al. Asthma control in patients receiving inhaled corticosteroid and long-acting beta2-agonist fixed combinations. A real-life study comparing dry powder inhalers and a pressurized metered dose inhaler extrafine formulation. BMC Pulm Med. 2011;11:40.

77. Allegra L, Cremonesi G, Girbino G, et al; PRISMA (PRospectIve Study on asthMA control) Study Group. Real-life prospective study on asthma control in Italy: cross-sectional phase results. Respir Med. 2012;106(2):205-214.
78. Terzano C, Cremonesi G, Girbino G, et al; PRISMA (PRospectIve Study on asthMA control) Study Group. 1-year prospective real life monitoring of asthma control and quality of life in Italy. Respir Res. 2012;13:112.

79. Sturton G, Persson C, Barnes PJ. Small airways: an important but neglected target in the treatment of obstructive airway diseases. Trends Pharmacol Sci. 2008;29(7):340-345.

80. Hogg JC, Chu F, Utokaparch S, et al. The nature of small-airway obstruction in chronic obstructive pulmonary disease. $N$ Engl J Med. 2004;350(26):2645-2653.

81. Saetta M, Di Stefano A, Turato G, et al. CD8+ T-lymphocytes in peripheral airways of smokers with chronic obstructive pulmonary disease. Am J Respir Crit Care Med. 1998;157(3 Pt 1): $822-826$.

82. Calverley PM, Kuna P, Monsó E, et al. Beclomethasone/formoterol in the management of COPD: a randomised controlled trial. Respir Med. 2010;104(12):1858-1868.

83. Tzani P, Crisafulli E, Nicolini G, et al. Effects of beclomethasone/ formoterol fixed combination on lung hyperinflation and dyspnea in COPD patients. Int J Chron Obstruct Pulmon Dis. 2011;6: 503-509.

84. Wedzicha JA, Singh D, Vestbo J; FORWARD Investigators. Extrafine beclomethasone/formoterol in severe COPD patients with history of exacerbations. Respir Med. 2014;108(8):1153-1162.

85. Linnane P, Voshaar T, Spinola M, et al. Usability evaluation of NEXThaler ${ }^{\circledR}$ versus Diskus ${ }^{\circledR}$ and Turbuhaler ${ }^{\circledR}$. Eur Respir J. 2012;40(Suppl 56): $313 \mathrm{~s}-314 \mathrm{~s}$.

86. Scuri M, Alfieri V, Giorgio A, et al. Measurement of the inhalation profile through a novel dry powder inhaler $\left(\mathrm{NEXThaler}^{\circledR}\right)$ in asthmatic patients using acoustic monitoring. Am J Respir Crit Care Med. 2013;187:A1931.

87. Sergio F, Chetta A, Pisi G, Aiello M, and Olivieri D: A novel NEXT DPI ${ }^{\circledR}$ dry powder inhaler and its use in asthmatic and COPD population. Eur Respir J. 2011;38(Suppl 55):140s.

88. Melani AS, Bonavia M, Cilenti V, et al; Gruppo Educazionale Associazione Italiana Pneumologi Ospedalieri. Inhaler mishandling remains common in real life and is associated with reduced disease control. Respir Med. 2011;105(6):930-938.

89. Voshaar T, Spinola M, Linnane P, et al. Comparing usability of NEXThaler $^{\circledR}$ with other inhaled corticosteroid/long-acting $\beta 2$-agonist fixed combination dry powder inhalers in asthma patients. $J$ Aerosol Med Pulm Drug Deliv. 2014;27(5):363-370.
Patient Related Outcome Measures

\section{Publish your work in this journal}

Patient Related Outcome Measures is an international, peer-reviewed, open access journal focusing on treatment outcomes specifically relevant to patients. All aspects of patient care are addressed within the journal and practitioners from all disciplines are invited to submit their work as well as healthcare researchers and patient support groups.

\section{Dovepress}

The manuscript management system is completely online and includes a very quick and fair peer-review system. Visit http://www.dovepress. com/testimonials.php to read real quotes from published authors. 